\title{
THE ORIGINS AND PALEOGENE HISTORY OF MODERN PLANT COMMUNITIES
}

GREENWOOD*, David R., Dept. of Geological Sciences, University of Saskatchewan, Saskatoon, SK, CANADA S7N 0W0; COLLINSON, Margaret E., Dept. of Geology, Royal Holloway \& Bedford New College, University of London, Egham, Surrey, TW20 0EX U.K.

Modern plant communities define global Biomes by their structure, floristics and physiognomy. The modern distribution and character of plant communities is determined by climate, large-scale biotic interactions and abiotic factors such as fire and other disturbance history. Biogeographic patterns also reflect past continental movements, dispersal, extinction and speciation events. The past distribution and history of the principal modern plant communities can be traced using key taxa and associations of taxa, and the foliar physiognomy of the biomal communities.

The antecedents of many modern types of vegetation can be found in the mixed plant communities of the Cretaceous and earlier. Late Cretaceous angiosperm radiation and $\mathrm{K} / \mathrm{T}$ extinctions substantially altered these plant communities, setting preconditions for subsequent evolution and the floristic character of terrestrial plant communities. Paleocene vegetation appears intermediate, and the main phase of floristic modernisation appears to have been during the Eocene.

Tropical rainforests and deciduous forests of a modern aspect are well represented in Eocene macrofloras at middle and higher palaeolatitudes respectively, in North America, Europe and Australia. These forests partly reflected present day phytogeographic provincialism but many taxa exhibited past cosmopolitanism, having much reduced modern ranges. The presence of "tropical" forests at middle latitudes, well outside their present day latitudinal extent, reflects the Early to Middle Eocene thermal maximum with widespread equable, humid and subhumid climates. At higher latitudes macrofloras reflect deciduous angiosperm vegetation of lower diversity than the middle latitude rainforests. Deciduousness in these forests was probably an adaptation to seasonal darkness beyond the palaeo-Arctic circle, but at intermediate latitudes may have reflected adaptation to greater temperature seasonality. Coniferous forests are represented in Eocene macrofloras from high latitudes and from uplands in the middle latitudes. Grasses are present in some Eocene macrofloras, but grasslands do not appear in the fossil record until the Oligocene or later. They seem to be a response to climatic deterioration and an evolving mammalian biota. Forested and herbaceous wetland communities may have been more diverse and latitudinally more uniform in the Palaeogene than today, but are otherwise quite modern. Post Oligocene history of most plant communities is that of climate altered distribution and floristic extinction. 